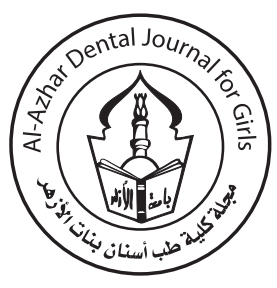

\title{
Effect of Thermo-Mechanical Aging on The Marginal Fit of Two Types of Monolithic Zirconia Crowns With Two Finish Line Designs
}

\author{
Khaled Haggag ${ }^{(1)}$, Muhammad Abbas, ${ }^{(2)}$ and Hussein Ramadan ${ }^{(3)}$
}

Codex : 14/1801

azhardentj@azhar.edu.eg

http://adjg.journals.ekb.eg

\section{KEYWORDS}

Thermo-Mechanical,

Marginal Fit,

Zirconia Crowns

\begin{abstract}
OBJECTIVES: The purpose of this study was to compare the marginal fit of two CAD/CAM monolithic zirconia crowns with two finish line designs after thermomechanical aging. MATERIALS AND METHODS: A total of 20 zirconia crowns were divided into two groups Bruxzir and Prettau zirconia $(n=10)$. Each type of zirconia crowns was divided into two groups according to the finish line design chisel $(\mathrm{CH})$ and deep chamfer (DC) groups $(\mathrm{n}=5)$ After cementation of crowns to their corresponding dies, the vertical marginal gap was measured then the all crowns of both groups were subjected to thermo-mechanical aging then the vertical marginal gap was measured again. RESULTS: Statistical analysis showed that. The thermo-mechanical aging significantly increased the vertical marginal gap where DC non-aged Bruxzir recording the lowest mean value $(31.41 \pm 5.9)$ and the $\mathrm{CH}$ aged Bruxzir recorded the highest mean value $(95.28 \pm 9.2)$ as indicated by three-way ANOVA test ( $\mathrm{F}=23.0741$, $\mathrm{p}=<0.0001<0.05)$. CONCLUSIONS: Thermo-mechanical aging significantly increased the vertical Marginal gap and the deep chamfer finish line preparation is preferred for construction of monolithic zirconia crowns.
\end{abstract}

\section{INTRODUCTION}

The popularity of ceramic restorations stems from the properties of the ceramic materials itself such as translucency, esthetic, and biocompatibility. ${ }^{1,2}$ The marginal fit is considered a very important criterion that should be carefully considered in the final restoration. ${ }^{3}$ Inaccurate fit creates potential space between the internal margin of restoration and the prepared tooth. As this space increases, and since most of luting cements are soluble in oral fluid, bacterial plaque can be accumulated at this defective area with subsequent gingival inflammation, caries, and pulpal lesions. ${ }^{4-6}$

1. Assistant Professor, Crowns and Bridges Department, Faculty of Dental Medicine, Al Azhar University, Egypt

2. Assistant Professor, Dental Biomaterials Department, Faculty of Dental medicine, Al-Azhar University, Egypt

3. Lecturer, Crowns and Bridges Department, Faculty of Dental Medicine, Al Azhar University, Egyp 
Many CAD/CAM systems including inoffice and laboratory have been introduced for production of both coping for ceramic veneer application and anatomic fully-contoured restorations out of ceramic blocks. ${ }^{5,7-9}$ One of the common misconceptions that the conventionally made restorations are more accurately fit than the CAD/CAM fabricated restorations..$^{10}$ in a study compared anterior $\mathrm{CAD} / \mathrm{CAM}$ manufactured zirconia restoration to a metal-ceramic one with sufficient number of samples and sufficient measurements per specimen found that there are no significant differences between both types of restorations and that both of them are within the clinically accepted range. ${ }^{11}$

The white opaque color of zirconia framework requires veneering with more esthetic glassy porcelain to achieve natural appearance of final restoration. ${ }^{12}$ However, cracking, chipping, and delamination of the porcelain veneer has been reported to be a major complication of these restorations..$^{13-15}$ Recently, fully contoured (monolithic) zirconia has been developed as an alternative and in order to overcome the failure of veneered zirconia restoration. . $^{12,16,17}$

Several investigators reported that the marginal fit of $\mathrm{CAD} / \mathrm{CAM}$ manufactured ceramic restorations was dependent on different factors such as veneering process, preparation convergence, cement space, and type of finish line. ${ }^{18-20}$ Monolithic zirconia enables the use of more conservative finish line designs. Some articles stated that some of the advantages of monolithic zirconia are reduction of breakage possibilities, avoiding chipping, high strength, minimal occlusal adjustment, and marginal accuracy ${ }^{21-23}$ Moreover, the assessment of thermo-mechanical aging may provide information about the long term stability of restoration. ${ }^{24}$

The purpose of the present study was to evaluate the effect of thermo-mechanical aging on the marginal fit of two types of monolithic zirconia crowns (Bruxzir and Prettau) with two finish line designs ( $1 \mathrm{~mm}$ deep chamfer, and $0.3 \mathrm{~mm}$ chisel). The null hypothesis was that the thermo-mechanical aging will have no effect on marginal fit of monolithic zirconia crowns.

\section{MATERIALS AND METHODS}

Two different types of monolithic translucent zirconia materials were used in this study shown in (table 1).

\begin{tabular}{|c|c|c|c|}
\hline Brand & Material type & Manufacturer & Lot \# \\
\hline Bruxzir & $\begin{array}{c}\text { Translucent } \\
\text { monolithic } \\
\text { zirconia }\end{array}$ & $\begin{array}{c}\text { Glidewell } \\
\text { Laboratories, } \\
\text { Irvine, USA }\end{array}$ & BZ0002762 \\
\hline Prettau & $\begin{array}{c}\text { Translucent } \\
\text { monolithic } \\
\text { zirconia }\end{array}$ & $\begin{array}{c}\text { Zirkonzahn, } \\
\text { Taufers, Italy }\end{array}$ & ZB6088A \\
\hline
\end{tabular}

\section{Master dies fabrication}

Two standard circular metal dies were milled by industrial lathe milling machine to simulate the preparation for mandibular first molar tooth. Each metal die prepared with flat occlusal surface and functional bevel, $5 \mathrm{~mm}$ occluso-gingival height, and $12^{\circ}$ degree axial taper, with two different finish line designs (one metal die with a circumferential $1 \mathrm{~mm}$ deep chamfer, and the other with $0.3 \mathrm{~mm}$ chisel finish line.

\section{Crowns fabrication}

A 10 Polyether impression (Impregum, 3M ESPE - Germany) was taken using custom made trays and 10 master resin dies were fabricated for each metal die.

All resin dies were sprayed by shera scan spray (Dentech Lab Supplies Ltd PO Box 87262 Meadow-bank, Auckland 1742) then, scanned via blue LED 3D dental scanner named Medit Identica Hybrid (Medit Company, 19 Inchon-ro 22-gil,Seongbuk-gu, Seoul, Korea82-2-2193-9600). The crowns are designed by Exocad cad system (Exocad GmbH, Julius-Reiber-Str. 37, D-64293 Darmstadt, Germany). The data of the completed design is merged and saved in a file, a 5-axis dental milling machine Roland DWX-51D (ROLAND DGA CORP. I 15363 BARRANCA PARKWAY I IRVINE, CALIFORNIA) was used to mill 20 zirconia crowns out of zirconia blanks. (Figure 1) 


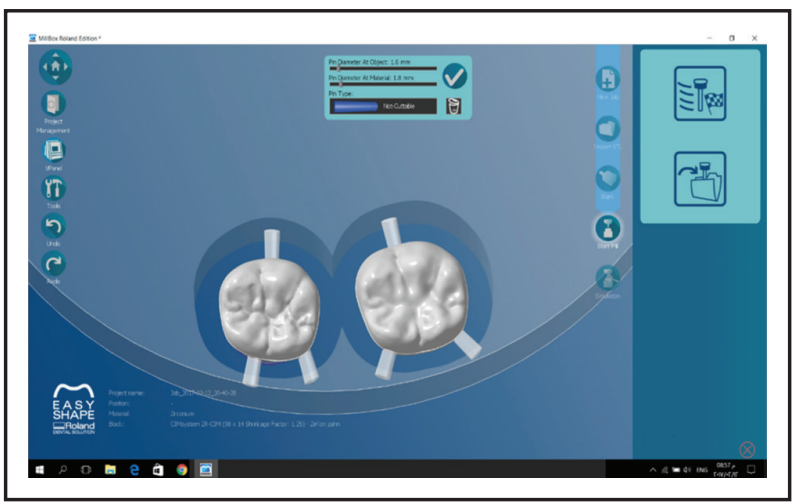

Fig. (1) Showing the type of material, blank size, its enlargement factor was inserted to the program and the selection of position of the restorations and their pins (nesting).

\section{Crowns assignment}

Twenty monolithic zirconia crowns were fabricated for this study, 10 crowns of (Bruxzir monolithic zirconia), and 10 crowns of (Prettau monolithic zirconia). Each 10 crowns were divided into two groups of 5 crowns according to the finish line design. DC group (1 $\mathrm{mm}$ deep chamfer) and $\mathrm{CH}$ group (0.3mm chisel).

All crowns were cemented to their corresponding dies using dual-curing self-adhesive resin cement (Theracem, BISCO, Inc. Schaumburg, IL60193 U.S.A) according to the manufacturer recommendation; half of each group was subjected to thermomechanical aging.

\section{Thermo-mechanical aging}

Mechanical aging test was conducted using the newly developed four stations multi-modal ROBOTA chewing simulator* integrated with thermo-cyclic protocol operated on servo-motor (Model ACH-09075DC-T, AD-Tech Technology CO., LTD., Germany). ROBOTA chewing simulator which has four chambers simulating the vertical and horizontal movements simultaneously in the thermodynamic condition. A weight of $5 \mathrm{~kg}$ which is comparable to $49 \mathrm{~N}$ of chewing force was exerted. The test was repeated 75000 times to clinically simulate the 6 months chewing condition. ${ }^{25}$

\section{Vertical Marginal Gap assessment before and after Thermo-mechanical aging}

Each specimen was photographed using USB Digital microscope with a built-in camera (Scope Capture Digital Microscope, Guangdong, China) connected with an IBM compatible personal computer using a fixed magnification of $110 \mathrm{X}$. A digital image analysis system (Image J 1.43U, National Institute of Health, USA) was used to measure and qualitatively evaluate the gap width. Within the Image $\mathbf{J}$ software, all limits, sizes, frames and measured parameters are expressed in pixels. Therefore, system calibration was done to convert the pixels into absolute real world units. Calibration was made by comparing an object of known size (a ruler in this study) with a scale generated by the Image $\mathbf{J}$ software. Samples were held in place over their corresponding dies using a specially designed and fabricated holding device. Shots of the margins were taken for each sample before and after thermo-mechanical aging. Then morphometric measurements were done for each shot 3 equidistant landmarks along the cervical circumference corresponding to each surface of the sample (Buccal, mesial, lingual, and distal). Measurement at each point was repeated five times.

Data analysis was performed in several steps. Initially, descriptive statistics for each group results. Three-way analysis of variance ANOVA test of significance was done for comparing variables $(\mathrm{Zr}$ ceramic, margin design and mechanical aging) affecting mean values. One-way ANOVA followed by pair-wise Tukey's post-hoc tests were performed if it showed significance between subgroups. Student t-test was performed to detect interaction between main groups with each margin and aging. Statistical analysis was performed using Asistat 7.6 statistics software for Windows (Campina Grande, Paraiba state, Brazil). $\mathrm{P}$ values $\leq 0.05$ are considered to be statistically significant in all tests. 


\section{RESULTS}

\section{Vertical Marginal Gap}

\section{For Bruxzir zirconia crowns;}

It was found that the highest vertical marginal gap mean \pm SD values were recorded with aged $\boldsymbol{C H}$ group (95.28 \pm 9.2$)$, while the lowest vertical marginal gap mean $\pm \mathrm{SD}$ values were for non-aged $D C$ group (31.41 \pm 5.9$)$. The difference between margin design groups was statistically significant as indicated by one-way ANOVA test $(\mathrm{F}=133.19$, $\mathrm{p}=<0.0001<0.05)$.

\section{For Prettau zirconia crowns;}

It was found that the highest vertical marginal gap mean $\pm \mathrm{SD}$ values were recorded with aged $\boldsymbol{D C}$ group; lowest vertical marginal gap mean \pm SD values were for non-aged $\boldsymbol{D C}$ group. The difference between margin design groups was statistically $(\mathrm{F}=36.15, \mathrm{p}=<0.0001<0.05)$. Tukey's post-hoc test showed no-significant $(\mathrm{p}>0.05)$ difference between aged groups - table (2) and figure (2)

\section{Bruxzir vs. Prettau}

With non-aged DC margin; it was found that Prettau group recorded statistically significant higher vertical marginal gap mean values than Bruxzir group as indicated by $\mathrm{t}$-test $(\mathrm{t}=17.6$, $\mathrm{p}=<0.0001<0.05$ )

\section{With aged DC margin;}

It was found that Prettau group recorded statistically significant higher vertical marginal gap mean values than Bruxzir group as indicated by t-test $(\mathrm{t}=12.47, \mathrm{p}=<0.0001<0.05)$

\section{With non-aged CH margin;}

It was found that Prettau recorded statistically significant higher vertical marginal gap mean values than Bruxzir as indicated by $\mathrm{t}$-test $(\mathrm{t}=2.26$, $\mathrm{p}=0.0297<0.05$ )

\section{With aged chesil margin;}

It was found that Bruxzir recorded statistically non-significant higher vertical marginal gap mean values than Prettau as indicated by $\mathrm{t}$-test $(\mathrm{t}=0.3143$, $\mathrm{p}=0.7551>0.05$ )

Totally, irrespective of margin design or aging, it was found that Prettau recorded statistically significant higher vertical marginal gap mean values than Bruxzir as indicated by three-way ANOVA test ( $F=$ $23.0741, p=<0.0001<0.05$ ).

Totally, regardless to type of zirconia or aging, it was found that $\mathrm{CH}$ margin design group recorded statistically significant higher vertical marginal gap mean values than DC margin design group as indicated by three-way ANOVA test $(F=174.52$, $p=<0.0001<0.05)$.

Table (2) Vertical marginal gap results (Mean values \pm SD) for both Zirconia ceramics as function of margin design and aging

\begin{tabular}{|c|c|c|c|c|c|}
\hline \multirow{2}{*}{ Variable } & \multicolumn{4}{|c|}{ Margin design } \\
\hline & \multicolumn{2}{|c|}{ DC } & \multicolumn{2}{c|}{ CH } & \\
\hline & Non-aged & Aged & Non-aged & Aged & \\
\hline \multirow{2}{*}{ Zr ceramic } & Bruxzir & $31.41^{\mathrm{d}} \pm 5.9$ & $62.35^{\mathrm{b}} \pm 6.9$ & $52.78^{\mathrm{c}} \pm 10.5$ & $95.28^{\mathrm{a}} \pm 9.2$ \\
\cline { 2 - 6 } & Prettau & $80.48^{\mathrm{b}} \pm 7.9$ & $95.05^{\mathrm{a}} \pm 6.4$ & $62.27^{\mathrm{c}} \pm 12.3$ & $94.07^{\mathrm{a}} \pm 8.9$ \\
\hline t-test & P value & $<0.0001^{*}$ & $<0.0001^{*}$ & $0.0297^{*}$ & $0.7551 \mathrm{~ns}$ \\
\hline
\end{tabular}

Different letters in same row indicating significant $(p<0.05)$ smd for columns $=3.45172 \quad *$; significant $(p>0.05)$
Significant minimum difference $($ smd) for rows $=3.45951$ $n s ;$ non-significant $(p>0.05)$ 


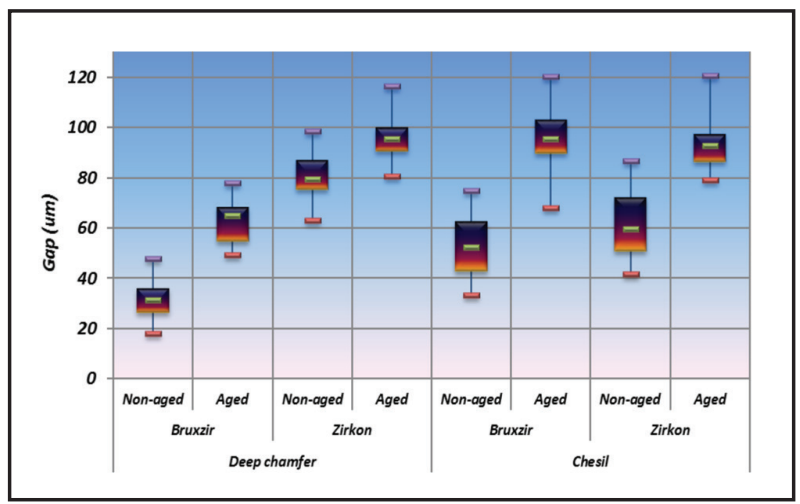

Fig. (2) Box plot showing vertical marginal gap mean values for both Zirconia ceramics as function of margin design and aging

Totally, irrespective of the type of zirconia or margin design, it was found that aged group recorded statistically significant higher vertical marginal gap mean values than non-aged group as indicated by three-way ANOVA test ( $F=371.7359$, $p=<0.0001<0.05$ ).

\section{DISCUSSION}

In the present study two standardized metal dies with two margin designs were used and duplicated with epoxy resin as a substitution to natural teeth to allow for fabrication of identical crowns, which is important for a reliable comparison of different groups. ${ }^{26}$

The metal dies were machine-milled to simulate a preparation of mandibular first molar for full coverage all-ceramic crown with $5 \mathrm{~mm}$ occlusogingival height, $8 \mathrm{~mm}$ cervical diameter according to other studies. ${ }^{24,27} \mathrm{~A}$ functional bevel is made to simulate clinical conditions and to achieve the exact positioning of the crowns on their corresponding dies. The total occlusal convergence angle was made $12^{\circ}$ as it was recommended that the proper convergence angle should be in a range of $10^{\circ}$ to $20^{\circ} .^{28}$ In addition, it was found that preparation angle of $12^{\circ}$ achieved the best overall precision of zirconia-based single crowns in range of 36.6 and $45.5 \mu \mathrm{m} .{ }^{29}$
The vertical marginal gap measurement was selected as it is one of the most frequently used methods to quantify the accuracy of fit of a restoration. The marginal fit was evaluated by direct viewing with external measurements using a digital microscope at fixed magnification of x100 this measurement technique has the advantage of being noninvasive and is, therefore, useful to determine the precision of fit of the whole restoration margin. ${ }^{5}$ all measurements were made by the same operator to avoid errors as much as possible.

Even though the results of this study support the rejection of the null hypothesis that the thermo-mechanical aging will have no effect on marginal fit of monolithic zirconia crowns the marginal discrepancies of the tested groups were within the threshold of clinical acceptability, the $120 \mu \mathrm{m}$ proposed by (McLean and Fraunhofer 1971). ${ }^{30}$

The thermo-mechanical aging performed in this study was found to significantly increase the vertical marginal gap. Although the critical aging temperature of zirconia suggested to be above $100^{\circ} \mathrm{C}$ ${ }^{31}$ which is far from the applied temperature in the present test $\left(5-55^{\circ} \mathrm{C}\right)$, it was found that artificial Aging significantly increased the vertical marginal discrepancy through thermo-mechanical loading. ${ }^{32}$ Also another study found that conducting $10 \mathrm{~h}$ of artificial aging for veneered specimens of (IPS e-max ZirCAD, Ivoclar) resulted in 55\% T/M phase transformation. ${ }^{33}$ Another explanation for the increased marginal gap with thermo-mechanical aging is related to the wash out of some of the luting cement at the margin as result of fluctuation of temperature during aging process. ${ }^{24}$

When we use the same scanning device, CADsoftware, and milling machine it seem to have no influence on the restorations marginal fit, ${ }^{34}$ however, the Prettau zirconia crowns recorded statistically significant higher marginal gap mean value than Bruxzir crowns, the reasons of this significant difference in the marginal fit are the difference in their chemical structure, the way of the manufacture of 
the zirconia material and consequently their different enlargement factors. The Glidewell Laboratories used the Colloidal technology in the manufacture of Bruxzir zirconia unlike the way of manufacture used by Zirkonzahn Company to manufacture the Prettau zirconia. These findings supported by study stated that the reason of the large contrast in internal fit between Lava and IPS ZirCAD crowns is the differences in material properties, sintering shrinkage, and dimensional stability between the two-zirconia systems. ${ }^{35}$ also another study revealed that the differences in marginal fit between each system result from zirconia blocks with various shrinkage rates depending on manufacturing company, scanning process, size of milling bur used, and the number of milling axis. ${ }^{36}$ in addition to the type of zirconia material itself might also affect the marginal fit. ${ }^{37}$

In the present study; regardless to zirconia type, the $\mathrm{CH}$ group recorded statistically significant higher marginal gap mean value than DC group. Although, the knife-edge finish line resulted in lower marginal opening values in another study they recommended shoulder and mini-chamfer in clinical application from biological and technical standpoint, as it triggers the wedging effect at the margin and may provide additional marginal bulk. ${ }^{38}$

However, these recommendations to avoid knifeedge margins are not supported by clinical study as they found that knife-edge margins allow clinical performance similar to that reported by other margin designs but with less invasive preparations. ${ }^{39}$ However, others do not support this, as the histological evidence was showing no difference in periodontal health among different patterns of margin designs. ${ }^{40,41}$ Moreover, knife-edge margins showed no more influence over gingival conditions than natural teeth in a sample of periodontal patients. ${ }^{42}$

The limitation of this study include the use of resin dies for measuring the marginal gap which doesn't represent the patient's mouth however, it is good for standardization. Also the vertical marginal gap was measured. The horizontal relationship was not quantified

\section{CONCLUSIONS}

Within the limitations of this study, the following conclusions were drawn:

1- The vertical marginal gap values of the tested groups were all within the clinically acceptable threshold $(120 \mu \mathrm{m})$.

2- Thermo-mechanical aging significantly increased the vertical marginal gap.

3- Deep chamfer finish line preparation is preferred with monolithic zirconia crowns.

\section{REFERENCES}

1. Conrad HJ, Seong WJ, and Pesun IJ. Current ceramic materials and systems with clinical recommendations: Asystematic review. J Prosthet Dent 2007;98:389-404.

2. Yucel MT, Aykent F, Avunduk MC. In vitro evaluation of the marginal fit of different all-ceramic crowns. J Dent Scie $2013 ; 8,225 \mathrm{e} 30$.

3. Giannetopoulos S, van Noort R, Tsitrou E. Evaluation of the marginal integrity of ceramic copings with different marginal angles using two different CAD/CAM systems. J Dent 2010;38:980-6.

4. Balkaya MC, Cinar A, and Pamuk S. Influence of firing cycles on the margin distortion of 3 all-ceramic crown systems. J Prosthet Dent 2005;93:346-55.

5. Hamza TA, Ezzat HA, El-Hossary MMK, Katamish HAE, Shokry TE. Rosenstiel SF. Accuracy of ceramic restorations made with two CAD/CAM systems. J Prosthet Dent 2013;109:83-7

6. Beuer F, Aggstaller H, Edelhoff D, Gernet W, Sorensen J. Marginal and internal fits of fixed dental prostheses zirconia retainers. Dent Mater 2009; 25:94-102.

7. Gu XH, Kern M Gu XH, Kern M. Marginal discrepancies and leakage of all-ceramic crowns: influence of luting agents and aging conditions. Int J Prosthodont 2003; 16:109-16.

8. Gonzalo E, Suárez MJ, Serrano B,Lozano JF. A comparison of the marginal vertical discrepancies of zirconium and metal ceramic posterior fixed dental prostheses before and after cementation. J Prosthet Dent 2009;102:378-84.

9. Grenade C, Mainjot A, Vanheusden A. Fit of single tooth zirconia copings: comparison between various manufacturing processes. J Prosthet Dent 2011;105:249-55. 
10. Pera $\mathrm{P}$, Gilodi $\mathrm{S}$, and Bassi F. In vitro marginal adaptation of alumina porcelain ceramic crowns. J Prosthet Dent 1994;72:585-90.

11. Kim YS and Yang JH. Marginal fit of the digident CAD/ CAM zirconia ceramic crowns. J Korean Acad Prosthodont 2006;44(3):275-83.

12. Miyazaki T, Nakamura T, Matsumura H, Ban S, Kobayashi T. Current status of zirconia restoration. J Prosthodont Res 2013; 57: 236-261.

13. Sailer I, Feher A, Filser F, Gauckler LJ, Lüthy H, Hämmerle $\mathrm{CH}$. Five-year clinical results of zirconia frameworks for posterior fixed partial dentures. Int J Prosthodont 2007; 20: 383-8.

14. Sailer I, Feher A, Filser F, Lüthy H, Gauckler LJ, Schärer P, Franz Hämmerle $\mathrm{CH}$. Prospective clinical study of zirconia posterior fixed partial dentures: 3-year follow-up. Quintessence Int 2006; 37: 685-93.

15. Vult von Steyern P, Carlson P, Nilner K. All-ceramic fixed partial dentures designed according to the DC-Zirkon technique. A 2-year clinical study. J Oral Rehabil 2005; 32: 180-7.

16. Ban S, Suzuki T, Yoshihara K, Sasaki K, Kawai T, Kono H. Effect of coloring on mechanical properties of dental zirconia. J Med and Bio Eng 2013;34(1): 24-9.

17. Stober T, Bermejo JL, Rammelsberg P, Schmitter M. Enamel wear caused by monolithic zirconia crowns after 6 months of clinical use. J Oral Rehabil 2014; 41: 314-22.

18. Kokubo Y, Ohkubo C, Tsumita M, Miyashita A, Vult von Steyern P, Fukushima S. Clinical marginal and internal gaps of Procera All Ceram crowns. J Oral Rehabil 2005;32:526-30.

19. Sulaiman F, Chai J, Jameson LM, Wozniak WT. A comparison of the marginal fit of In- Ceram, IPS Empress, and Procera crowns. Int J Prosthodont 1997;10:478-84.

20. Albert FE and El-Mowafy O. Marginal adaptation and microleakage of Procera All Ceram crowns with four cements. Int J Prosthodont 2004;17(5):529-35.

21. Lazetera A. Extreme class II full arch zirconia implant bridge. Australasian Dental Practice, 2009; 7: 170-4.

22. Guess PC, Att W, Strub JR. Zirconia in fixed implant prosthodontics. Clinical Implant Dentistry and Related Research, 2012; 14(5): 633-45.

23. Carames J, Suinaga LT, Yu YCP, Pérez A, Kang M. "Clinical Advantages and Limitations of Monolithic Zirconia Restorations Full Arch Implant Supported Reconstruction: Case Series". International Journal of Dentistry.2015
24. Att W, Komine F, Gerds T, Strub JR. Marginal adaptation of three different zirconium dioxide three-unit fixed dental prostheses. J Prosthet Dent 2009;101:239e47.

25. Nawafleh N, Hatamleh M, Elshiyab S, Mack F.Lithium Disilicate Restorations Fatigue Testing Parameters: A Systematic Review.J Prosthodont. 2016 Feb;25(2):116-26.

26. Studart AR, Filser F, Kocher P, Gauckler LJ. Fatigue of zirconia under cyclic loading in water and its implications for the design of dental bridges. Dent Mater;23:106-14.

27. Miura S, Nagaki R, Kasahara S, Yoda M. Fit of zirconia all-ceramic crowns with different cervical margin designs, before and after porcelain firing and glazing. Dent Mater J, 2014; 33(4): 484-9.

28. Goodacre CJ, Campagni WV, Aquilino SA. Tooth preparations for complete crowns: an art form based on scientific principles. J Prosthet Dent 2001; 85:363-76.

29. Beuer F, Edelhoff D, Gernet W, Naumann M. Effect of preparation angles on the precision of zirconia crown copings fabricated by CAD/CAM system. Dent Mater J 2008; 27:814-20.

30. McLean JW and Von Fraunhofer JA. The estimation of cement film thickness by an in vivo technique. J Br Dent 1971;131:107-11.

31. Kim HT, Han JS, Yang JH, Lee JB, Kim SH. The effect of low temperature aging on the mechanical property \& phase stability of Y-TZP ceramics. J Adv Prosthodont 2009;1:113e7.

32. El-Dessouky RA, Salama MM, Shakal MA, Korsel AM. Marginal adaptation of CAD/CAM zirconia-based crown during fabrication steps. Tanta dental journal 2015;12:81-8

33. Kim JW, Covel NS, Guess PC, Rekow ED, Zhang Y. Concerns of hydrothermal degradation in CAD/CAM zirconia. J Dent Res 2010;89:91e5.

34. Borba M, Cesar PF, Griggs JA, Bona ÁD. Adaptation of allceramic fixed partial dentures. Dent Mater 2011;27:1119-26.

35. Yildiz C, Vanlioglu BA, EVREN B, ULUDAMAR A, ÖZKAN Y K. Marginal-internal adaptation and fracture resistance of CAD/CAM crown restorations. Dent Mater J, 2013; 32(1): 42-7.

36. Ji MK, Park JH, Park SW, Yun KD, Oh GJ, Lim HP. Evaluation of marginal fit of two CAD-CAM anatomic contour zirconia crown systems and lithium disilicate glass-ceramic crown. J Adv Prosthodont 2015;7:271-7 
37. Song TJ, Kwon TK, Yang JH, Han JS, Lee JB, Kim SH, Yeo IS. Marginal fit of anterior 3-unit fixed partial zirconia restorations using different CAD/CAM systems. J Adv Prosthodont, 2013; 5:219-25.

38. Comlekoglu M, Dundar M, Ozcan M, Gungor M, Gokce B, Artunc C. Influence of cervical finish line type on the marginal adaptation of zirconia ceramic crowns. Oper Dent, 2009 Sep-Oct; 34(5):586-92.

39. Poggio CE, Dosoli R, Ercoli C. A retrospective analysis of 102 zirconia single crowns with knife-edge margins.
J Prosthet Dent 2012; 107:317-21 .

40. Lang NP. Periodontal considerations in prosthetic dentistry. Periodontology 2000 1995; 9:118-31.

41. Carnevale G, Sterrantino SF, Di Febo G. Soft and hard tissue wound healing following tooth preparation to the alveolar crest. Int J Periodontics Restorative Dent 1983; 3:36-53.

42. Carnevale G, Di Febo G, Fuzzi M. A retrospective analysis of the perio-prosthetic aspect of teeth re-prepared during periodontal surgery. J Clin Periodontol 1990; 17:313-6. 